\title{
Evolving
}

Technology

\section{Autologous glue: Part of the sticky mystery unraveled}

\author{
Guido J. Van Nooten, MD, PhD, ${ }^{a}$ Pamela Somers, BSc, ${ }^{a}$ Ramses Forsyth, MD, ${ }^{\mathrm{b}}$ Kishan Narine, MD, PhD, \\ Yves Van Belleghem, MD, BSc, ${ }^{a}$ Stefaan Jacobs, MD, and Filip De Somer, PhD $^{a}$
}

Objective: The aim of the study was to evaluate the safety and efficacy of an autologous surgical tissue adhesive.

Methods: Autologous glue was made out of canine concentrated plasma proteins mixed with $7.5 \%$ glutaraldehyde. Tensile strength and cytotoxicity of the autologous glue were tested. In a dog model, 8 transectioned iliac arteries were reanastomosed by using the animal's glue as the sole fixation method. After 120 days, all animals were angiographically controlled for patency and killed for histologic and immunohistochemical examination of the anastomosis.

Results: The autologous glue showed sufficient tensile strength $\left(557 \pm 135 \mathrm{~N} / \mathrm{mm}^{2}\right)$. The elasticity of the glue is influenced by variations of concentrations in both proteins and glutaraldehyde. Glutaraldehyde remained cytotoxic, even at low concentrations of $2.5 \%$. All operative procedures were successful. Angiographs performed before animal death showed all but 1 vessel to be patent and showed manifest compression signs in 3 anastomoses. Histological examination revealed only a foreign-body reaction adjacent to the surface of the glue. The autologous glue does not trigger any immune response on immunochemistry. Because fibroblastic neo-endothelial lining was near to normal, potential glutaraldehyde leaching does not seem too harmful for the vascular juncture in the dog model.

Conclusions: Autologous glutaraldehyde glue has been used successfully as a vascular adhesive. In contrast to our previous studies with heterologous glue, we did not find a fierce acute inflammatory reaction indicating immune triggering. Nevertheless, glutaraldehyde remains a cytotoxic cross-linker. It is yet not known whether autologous glutaraldehyde glue can be used safely in clinical practice.

From the Heart Center ${ }^{\mathrm{a}}$ and the Department

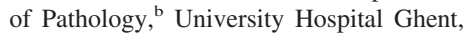
Ghent, Belgium.

Received for publication Jan 25, 2007; revisions received March 16, 2007; accepted for publication April 2, 2007.

Address for reprints: Guido J. Van Nooten, $\mathrm{MD}, \mathrm{PhD}$, Cardiac Surgery Department 5K12, University Hospital Ghent, Belgium, De Pintelaan 185, 9000 Ghent, Belgium (E-mail: guido.vannooten@UGent.be).

J Thorac Cardiovasc Surg 2007;134:415-23

$0022-5223 / \$ 32.00$

Copyright (C) 2007 by The American Association for Thoracic Surgery

doi:10.1016/j.jtcvs.2007.04.003

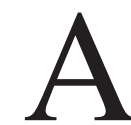

lthough manual suturing remains the gold standard, the quest for alternative methods to create the perfect vascular juncture is still ongoing. In the past, various types of glue have been used to secure an anastomosis, with diverse results. Most of the initial research on glues was focused on sealants to seal off liquid or gas leaks. Several studies demonstrated the efficacy of fibrin sealants in different types of operations. ${ }^{1}$ This first generation of sealants used bovine components in part. The immune response to bovine components can lead to severe anaphylactic reactions when the patient is re-exposed to the product. ${ }^{2}$ In addition to fibrin sealants, other types of glue have been used. Initially, cyanoacrylic glues showed good tensile strength but caused deterioration of the vascular wall. ${ }^{3}$ On the other hand, because of their good mechanical profile component, protein-aldehyde glues are frequently used for vascular repair in clinical practice. The utility of the 3-component gelatin-resorcinol-formaldehyde (GRF) glue (Cardial Technopole, St 


\author{
Abbreviations and Acronyms \\ $\mathrm{GRF}=$ gelatin-resorcinol-formaldehyde \\ MTS = [3-(4,5-dimethylthiazol-2-yl)-5-(3-carboxymeth- \\ oxyphenyl)-2-(4-sulfophenyl)-2H-tetrazolium, \\ inner salt] \\ PBS $=$ phosphate-buffered saline \\ TIMI $=$ Thrombolysis In Myocardial Infarction
}

Etienne, France) as adjuvant treatment in aortic dissection was already obvious in the 1970s. ${ }^{4}$ We previously demonstrated the feasibility of coronary anastomoses using BioGlue, which is composed of bovine serum albumin $(45 \%$ solution) and glutaraldehyde (10\% solution; CryoLife Inc, Kennesaw, Ga) as the sole adhesive with acceptable results. ${ }^{5}$ The major disadvantages of these polymerized component glues are their stiffness and potential toxicity and the fact that some components come from another species than the acceptor, which can trigger immune reactions. To cope with the latter and to comply with the European directive starting January 2007 to ban the use of bovine products, the search for autologous adhesives is on. We were particularly interested in the immunohistologic host reaction using a 2-component autologous protein glue as adhesive. This article describes the results of the use of a cross-linked protein substrate as a surgical tool to perform sutureless vascular anastomoses in an experimental dog model.

\section{Materials and Methods \\ Fabrication of the Glue}

In the dog model $75 \mathrm{~mL}$ of blood was drawn through a vein puncture into a syringe containing $6 \mathrm{~mL}$ of citrate (Baxter, Brussels, Belgium) from each animal before the start of the surgical procedure. After centrifugation, approximately 30 to $45 \mathrm{~mL}$ of plasma was obtained, and consequently, all cells were retransfused to the animal.

Our 2-component autologous glue was made by mixing a defined plasma concentrate with 7.5\% glutaraldehyde (VWR International, Leuven, Belgium). Previous in vitro testing revealed that a 4-fold protein concentration from average baseline is the ideal substrate for the making of a firm but elastic glue independent of the species (human, bovine, or canine) (De Somer et al, 2007, unpublished data). Also, the glutaraldehyde concentration $(2.5 \%-15 \%)$ linearly predicts the speed of the polymerization (from several minutes up to a few seconds). Ten to $15 \mathrm{~mL}$ of canine plasma was ultracentrifuged for 60 minutes at $3800 \mathrm{~g}$ in an Amicon Ultra-15 filter unit (Millipore Corp, Billerica, Mass) to obtain the exact protein content of the plasma concentrate. The preconcentration and postconcentration values of albumin were determined by using a modular machine (Roche, Brussels, Belgium), and fibrinogen concentrations were analyzed on an STA-R device (Roche, Brussels, Belgium; Table 1). Once the ideal concentration of at least $100 \mathrm{~g} / \mathrm{L}$ albumin and $5 \mathrm{~g} / \mathrm{L}$ fibrinogen is reached, the concentrate and $7.5 \%$ glutaraldehyde are loaded in a Mixpac
TABLE 1. Protein content of the canine concentrate $(n=3)$

\begin{tabular}{lcr}
\hline & Plasma & 60-min sample \\
\hline Albumin & $29.5 \pm 3.3 \mathrm{~g} / \mathrm{L}$ & $146.5 \pm 33.3 \mathrm{~g} / \mathrm{L}$ \\
Fibrinogen & $1.55 \pm 0.38 \mathrm{~g} / \mathrm{L}$ & $8.08 \pm 2.91 \mathrm{~g} / \mathrm{L}$ \\
\hline
\end{tabular}

mixing device (Mixpac, Rotkreuz, Switzerland). After careful deairing, a small mixing tip is mounted on top of the cartridge, and the sample is applied. Full holding power is achieved within 90 seconds.

\section{Tensile Strength}

Tensile strength was evaluated with the "Pull to Break" test program of a Lloyd LF Plus digital testing machine (Analis, Suarlée, Belgium). Two milliliters of glue was applied on 2 aluminum blocks. Three minutes after application, the blocks were loaded on the Lloyd LF Plus holders and separated at a pulling speed of $10 \mathrm{~mm} / \mathrm{min}$. Tissucol Duo (Tisseel; Baxter, Brussels, Belgium) and BioGlue were also tested.

\section{Elasticity Testing}

The elasticity of BioGlue and autologous canine glue was tested with a Loyd LF Plus universal material tester (Analis). The build-in "Push to Maximum Load" test program was used for the analysis. Two milliliters of glue was applied in a plastic vial. Twenty minutes after application, a metal rod with a diameter of $15.9 \mathrm{~mm}$ was placed on top of the glue and pushed $3 \mathrm{~mm}$ into the glue at a rate of $1 \mathrm{~mm} / \mathrm{min}$.

\section{Cytotoxicity Study}

The source of plasma used in this experiment is canine. The test samples were allowed to polymerize about 15 minutes before the cell-culture experiment. The samples were not really sterilized. The plasma concentrate was handled with sterile material. The glutaraldehyde solutions were filtered with a sterile filter unit (Millex, $33 \mathrm{~mm}$; Millipore, Billerica, Mass). The mixing of the plasma and glutaraldehyde was performed with sterile material. All steps were carried out in a sterile laminar flow cabinet with sterile material. The same type of glue was used to fix the samples to the bottom of each well. The glue was allowed to set about 15 minutes before adding the cells. The compatibility of each test sample was evaluated by using an in vitro cell-culture assay. The cells used in the cytotoxicity study were chicken embryo fibroblasts. The cells were cultured in $75-\mathrm{cm}^{2}$ tissue-culture flasks (Cellstar; Greiner Bio-One, Wemmel, Belgium) in Dulbecco's modified Eagle's medium (Gibco, Invitrogen, Merelbeke, Belgium) supplemented with $10 \%$ fetal calf serum (Gibco, Invitrogen). The cell culture was maintained in a humidified incubator at $37^{\circ} \mathrm{C}$ at $5 \% \mathrm{CO}_{2}$ in air. In the cell-culture assay 16 -mm-diameter specimens cut from each sterile test sample were glued on the bottom of each well in a 24-well plate (Cellstar, Greiner Bio-One, Belgium; the diameter of each well is about $16 \mathrm{~mm}$ ). Subsequently, chicken embryo fibroblasts at $4 \times 10^{4}$ cells per well were seeded evenly on the test specimens in $200 \mu \mathrm{L}$ of Dulbecco's modified Eagle's medium supplemented with $10 \%$ FCS. The cell culture was maintained in a humidified incubator at $37^{\circ} \mathrm{C}$ with $5 \%$ 
$\mathrm{CO}_{2}$ in air. Therefore the test material was placed in direct contact with the cell layer for 24 and 48 hours. By using the [3-(4,5dimethylthiazol-2-yl)-5-(3-carboxymethoxyphenyl)-2-(4-sulfophenyl)-2H-tetrazolium, inner salt] (MTS) assay (Promega, Madison, Wis), the viable cells cultured on each test specimen were determined 24 to 48 hours after cell seeding. The cells cultured on each test specimen were washed with phosphate-buffered saline (PBS) twice, and viable cell numbers then were determined indirectly by the conversion of MTS into a soluble dye. The MTS assay is based on the conversion of MTS into aqueous soluble formazan by mitochondrial dehydrogenase enzymes found in metabolically active cells. The quantity of formazan product, as measured by the amount of 490-nm absorbance, is directly proportional to the number of living cells in culture. In the test $100 \mu \mathrm{L}$ of MTS solution was added to the culture wells. After 4 hours at $37^{\circ} \mathrm{C}$ in a humidified $5 \% \mathrm{CO}_{2}$ atmosphere, the absorbance at $490 \mathrm{~nm}$ was recorded by using an ELISA plate reader (EL 800, Universal Microplate Reader; Bio-Tek, Winooski, Vt).

\section{Animal Model}

Four mongrel dogs had both their external iliac arteries repaired by means of gluing after total surgical section of the arteries. Average age of the exbreeder female dogs was 8.9 years (7.5-11.2 years), and average weight was $13.4 \mathrm{~kg}(10-17 \mathrm{~kg})$. No vaccines that had been in contact with bovine albumin were previously administered to the animals. The dogs fasted for 24 hours and were premedicated. Once the animal was positioned in the supine position, a peripheral intravenous line was placed in the left upper limb. Fifteen milligrams per kilogram of cephalosporin was injected intramuscularly for antibiotic prophylaxis, and intravenous crystalloid fluids were given for maintenance. A 3-lead electrocardiogram was used to monitor heart rate and rhythm. Propofol, 0.5 $\mathrm{mg} / \mathrm{kg}$ (Diprivan 2\% Emulsion; AstraZeneca, Ghent, Belgium), was administrated before tracheal intubation. Ventilation parameters were adjusted to keep the blood gas values within normal range. Anesthesia was maintained by using intravenous propofol, 4 to $8 \mathrm{mg} \cdot \mathrm{kg}^{-1} \cdot \mathrm{h}^{-1}$; fentanyl, $1 \mu \mathrm{g} / \mathrm{kg}$ (Janssen Pharmaceutica, Beerse, Belgium); and pancurorium, $0.1 \mathrm{mg} / \mathrm{kg}$, for muscle relaxation. Incisions were made in both groins to expose the iliac arteries. Arteries were dissected and snared. One milligram per kilogram of heparin was administered, and the iliac arteries were clamped before complete transection. Both ends were fixed with two 7-0 monofilament extravascular stitches to avoid retraction. Consequently, both ends were slid over a 5-mm balloon catheter introduced $2 \mathrm{~cm}$ more distally by direct puncture. The margins were manually positioned end to end after balloon inflation. Two milliliters of autologous canine glue was applied and dried for 2 minutes. The distal elastic snares were removed, and the anastomosis was opened after 5 minutes. After hemostatic control, the incision was closed in layers with insertion of a small drain. After extubation, the dogs were kept in the recovery room for 4 hours. Care was taken for catheters and the drain, which were progressively removed. Once daily, cephalosporin was administered intramuscularly. Analgesics were given as necessary. After 4 hours and after all medication had been given, the animal was returned to a controlled animal facility, where the general health of the dog was checked daily. The Ethical Committee for Animal Experimentation of the University of Ghent approved all procedures (Protocol
03/21). All animals received care in conformation with international and Belgian legislation. ${ }^{6}$

\section{Angiographic Analysis}

Immediately postoperatively and at 120 days (before death), angiographic analysis was performed after achievement of general anesthesia.

\section{Light Microscopic Analysis}

The anastomotic site was longitudinally transected, and samples for histologic analysis were fixed in $4 \%$ phosphate-buffered formaldehyde and embedded in paraffin. Tissues were cut at 5- $\mu \mathrm{m}$ sections and mounted on poly-L-lysine-coated slides. Hematoxylin and eosin staining was performed for routine histologic evaluation, Masson trichrome staining for collagen, Orcin staining for elastin, and myeloperoxidase staining for granulocytes. Monoclonal antibodies (with cross-reactivity to canine origin) were used to detect macrophages (MAC-1; Serotec, Oxford, United Kingdom). Ultrathin sections $(60 \mathrm{~nm})$ of the anastomosis were prepared for examination with a Zeiss EM 900 transmission electron microscope. Tissue specimens were embedded in Epon (Hexion Specialty Chemicals, Houston, Tex) and stained with uranylacetate and lead citrate.

\section{Immunohistochemical Analysis}

Immunohistochemical analysis was performed to detect helper/ inducer T cells (CD4; Novocastra, Newcastle upon Tyne, United Kingdom; dilution 1:20), suppressor/cytotoxic T cells (CD8; Novocastra; dilution 1:20), and macrophages (CD68; Dakocytomation, Glostrup, Denmark; dilution 1:2000). Five-micrometer-thick paraffin sections were fixed in formaldehyde, blocked with normal horse serum, and incubated with unlabeled primary antibodies at room temperature followed by PBS washing and then incubated with biotinylated secondary antibodies at room temperature. Primary antibodies included mouse anti-CD4, mouse anti-CD8, and mouse anti-human CD68 antibody. The sections were blocked with peroxidase solution followed by PBS washing and incubated with biotinylated horse anti-mouse $\mathrm{IgG}$ at room temperature (Vector Laboratories, Burlingame, Calif; dilution 1:500). After rewashing with $\mathrm{PBS}$, sections were incubated with horseradish peroxidase-avidin-biotin complex solutions at 1:500 dilution (Vector Laboratories). Specific antibody binding was detected with 3,3'-diaminobenzidine and counterstained with hematoxylin.

\section{Statistical Analysis}

Statistical analysis was performed with SPSS 12.0 (SPSS Inc, Chicago, Ill). Analysis of variance was performed with the posthoc Bonferroni correction to establish differences between groups.

\section{Results}

\section{Tensile Strength}

The start values of fibrinogen and albumin in the canine plasma were 1.27 and $32.5 \mathrm{~g} / \mathrm{L}$, respectively. After 60 minutes of centrifugation in the Amicon ultrafilter, fibrinogen and albumin concentrations increase to 8.78 and 144.4 $\mathrm{g} / \mathrm{L}$, respectively. Mixing of this protein concentrate with $2.5 \%, 5 \%$, and $7.5 \%$ glutaraldehyde $(\mathrm{n}=3$ each) resulted in 
Stress at maximum load

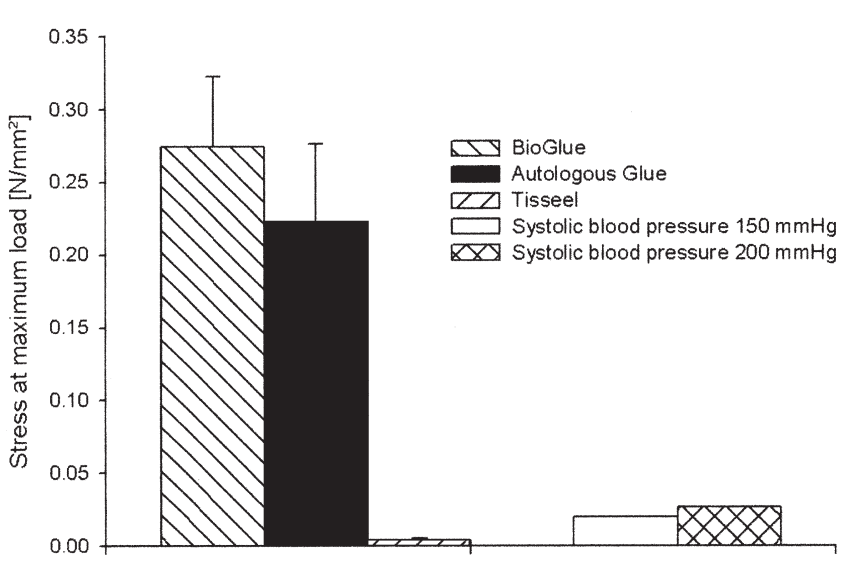

Figure 1. Tensile strength test results.

a respective load of $300 \pm 54,385 \pm 52$, and $557 \pm 135 \mathrm{~N}$. The maximum load for Tissucol Duo and BioGlue was $11 \pm$ 2 and $686 \pm 120 \mathrm{~N}$, respectively. Tensile strength was equal for the $7.5 \%$ glutaraldehyde autologous glue $(\mathrm{n}=3)$ and BioGlue (n $=3, P=.23$ ) but inadequate for Tisseel ( $\mathrm{n}=3$, $P<.001)$. The values for tensile strength at maximum load are converted into stress at maximum load (Newtons per square millimeter). The conversion gives a stress at maximum load for autologous glue made from canine proteins of $0.17 \mathrm{~N} / \mathrm{mm}^{2}$. Both glutaraldehyde glues can by 10 -fold resist the strength exercised of a systolic arterial pressure at $150 \mathrm{~mm} \mathrm{Hg}\left(0.016 \mathrm{~N} / \mathrm{mm}^{2}\right.$, Figure 1).

\section{Elasticity Testing}

BioGlue analysis $(\mathrm{n}=5)$ revealed a mean maximum load of $322 \pm 104 \mathrm{~N}$ and a work to limit of $0.4 \pm 0.1 \mathrm{~J}$, whereas the canine autologous glue $(\mathrm{n}=6)$ showed much lower values of $144 \pm 66 \mathrm{~N}(P=.002)$ for maximum load and $0.2 \pm 0.1$ $\mathrm{J}$ for work to limit $(P<.001)$.

\section{Operative Procedures}

Direct sutureless reanastomosis with autologous glue was performed in all 8 external iliac arteries (Figure 2). Only 2 $\mathrm{mL}$ of autologous surgical tissue adhesive was used to secure the end-to-end anastomosis in our canine model. On 3 occasions, we used more than $2 \mathrm{~mL}$ of glue. In dog number 1 (right side) some extra glue was applied to stop the anastomotic oozing without reclamping the artery. In dog number 3 (right side) the liquid only slowly polymerized and never achieved full holding power. Because of incessant bleeding, we reclamped the vessel. This particular dog had very low preoperative albumin (12.7 g/L) and low fibrinogen $(0.149 \mathrm{~g} / \mathrm{L})$ levels. We suspected an overly low albumin concentrate (which was measured afterward at 46.8 $\mathrm{g} / \mathrm{L}$ ), and therefore we centrifuged the plasma proteins for

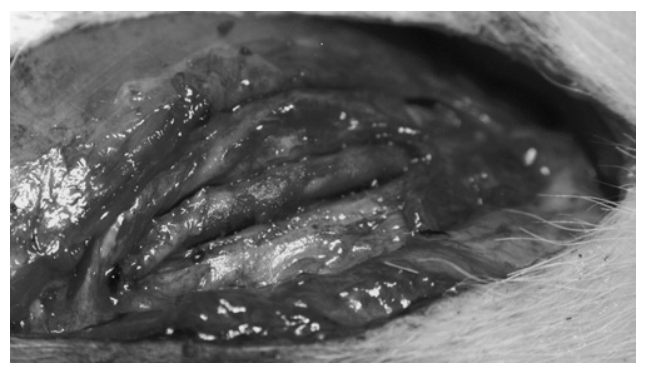

Figure 2. Operative view of canine iliac artery anastomosis before death.

another 30 minutes (to a final concentration of $78.9 \mathrm{~g} / \mathrm{L}$ of albumin). An extra of $2 \mathrm{~mL}$ of the more concentrated glue was prepared. The second application was successful. Also, in the same animal at the left side, we applied more than 2 $\mathrm{mL}$ of the concentrated 90-minute glue. Average temporary arterial occlusion time was recorded at $6.2 \pm 2.0$ minutes. All animals survived the initial procedure. One animal presented with an important hematoma in the left groin on the first operative day (dog number 1, right side). No signs of leg ischemia were recorded.

\section{Angiographic Analysis}

All survivors underwent an angiographic scan immediately after the operative procedure. Flow was assessed according to the Thrombolysis In Myocardial Infarction (TIMI) protocol for coronary arteries. ${ }^{7}$ All anastomoses were patent immediately postoperatively. Perfect runoff of the iliac artery (TIMI flow 3) without signs of distal alteration of the circulation was recorded in 6 vessels. Two animals presented with clear tapering at the anastomotic site. Also, before death, all animals had a second angiography. Perfect runoff of the iliac artery (TIMI flow 3) without signs of distal alteration of the circulation was recorded in 4 vessels. One vessel was totally occluded (dog number 3 , right side). Two vessels presented with vascular string formation at the anastomotic site, and 1 (dog number 1, right side) presented with a clear sandglass sign with impaired visualization of the distal vascular bed (Figure 3). No additional collateral flow was observed distal to the anastomoses. Table 2 concentrates the operative and angiographic data with the macroscopic findings and grading of the inflammatory response at the anastomotic sites of all the animals.

\section{Histologic and Immunohistochemical Analysis}

A light microscopic scan showed a mild chronic inflammatory reaction around the islets of glue, with infiltration of very few lymphocytes and plasma cells. The glue material was surrounded by a chronic inflammatory perimeter consisting of mainly macrophages and some fibroblastic cells. The absence of $\mathrm{CD}^{+} \mathrm{T}_{\mathrm{H}}$ lymphocytes indicates the ab- 


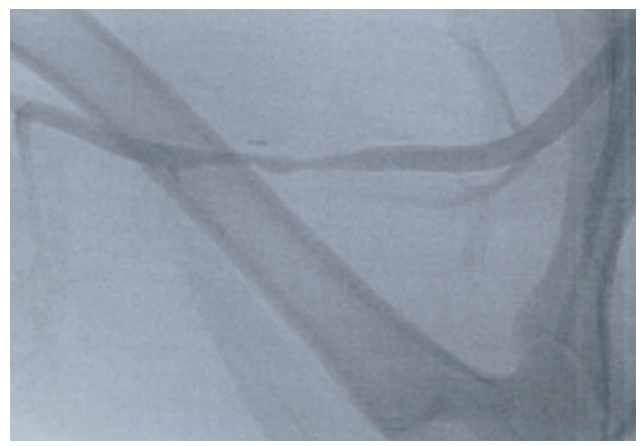

Figure 3. Angiographic control of the iliac anastomosis. Note the narrowing of the vessel caused by mechanical compression marked by a hemoclip on top.

sence of antigen presentation (Figure 4). CD8 staining shows similar findings as with an anti-CD4 immunohistochemistry. Again, the absence of $\mathrm{CD}^{+}$killer T lymphocytes supports the hypothesis of a negligible immune response (Figure 5). The glue is surrounded by a perimeter of dense layers of macrophages (palisade formation) adjacent to the intact surface of the glue and some fibroblasts (Figure 6). A sharp delineation exists between these macrophages and the glue deposit (CD68). Rarely, a macrophage invading the glue deposit can be noted. Some remnants of the glue are digested by macrophages and giant cells. The highest density of macrophages was counted in the lamina elastica externa, acting as a filter for the migrating macrophages. Around older and more fragmented islets, a foreign-body reaction appeared with giant cell formation. A new endothelial lining (CD4) was already present in most of the cases at the site of the vascular junction. Also, few infiltrations of elastin fibers (Orcin) of the vessel wall into the intima were noticed. The chronic inflammatory reaction is mild compared with the fierce acute inflammation we found in previous testing with BioGlue or heterologous glue (myeloperoxidase). Severe infiltration of nonmacrophages (predominantly lymphocytes and some granulocytes) was only present in the 2 anastomoses with marked postoperative bleeding (dogs number 1 and 3, right side). Electron microscopic scanning confirmed the predominant foreign-body reaction and the absence of active granulocytes.

\section{Toxicity Test}

Toxicity became clearly more important for increasing concentrations of glutaraldehyde. Even the lowest dose of $2.5 \%$ glutaraldehyde showed a distinct cytotoxicity after 24 hours of exposure compared with control values (Figure 7).

\section{Discussion}

In the past, several types of glue have been used to secure a vascular anastomosis, with various results. Earlier at-

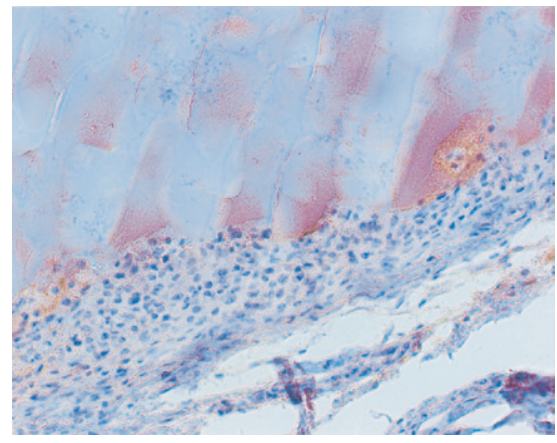

Figure 4. CD4. Glue material surrounded by a chronic inflammatory perimeter consisting of mainly macrophages and fibroblastic cells is shown. Note the absence of $\mathrm{CD}^{+}$lymphocytes indicating no antigen presentation. (Original magnification $400 \times$.)

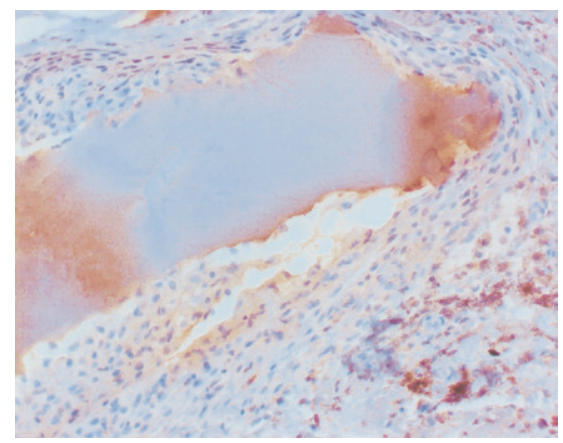

Figure 5. CD8. This illustration shows more or less similar findings as with an anti-CD4 immunohistochemical scan. Note again the absence of $\mathrm{CD8}^{+}$killer T lymphocytes. (Original magnification $400 \times$.)



Figure 6. Palisade formation of macrophages is shown. Together with the sharp border between the mild inflammation and the glue deposits and the relative absence of granulocytes, these findings support the hypothesis that this type of glue only triggers a foreign-body reaction. (Hematoxylin and eosin staining, original magnification $400 \times$.) 
TABLE 2. Operative outcome, angiographic data, and inflammatory response

\begin{tabular}{|c|c|c|c|c|c|c|c|}
\hline & Bleeding & Hematoma & $\begin{array}{c}\text { TIMI, } \\
\text { postoperative }\end{array}$ & $\begin{array}{l}\text { TIMI, } \\
120 \text { d }\end{array}$ & Macro findings & $\begin{array}{l}\text { Inflammation: } \\
\text { macrophages }\end{array}$ & $\begin{array}{c}\text { Inflammation: } \\
\text { nonmacrophages }\end{array}$ \\
\hline Dog 1, left & & & 3 & 3 & & + & + \\
\hline Dog 1, right & + & ++ & 2 & 1 & Glue +++ & +++ & $+++^{*}$ \\
\hline Dog 2, left & & & 3 & 2 & & ++ & ++ \\
\hline Dog 2, right & & & 3 & 3 & & + & + \\
\hline Dog 3, left & & & 3 & 2 & Glue +++ & ++ & + \\
\hline Dog 3, right & +++ & & 2 & 0 & Glue +++ & ++ & $+++^{*}$ \\
\hline Dog 4, left & & & 3 & 3 & & + & + \\
\hline Dog 4, right & & & 3 & 3 & & ++ & ++ \\
\hline
\end{tabular}

TIMI, Thrombolysis In Myocardial Infarction. TIMI flow: 3, unobstructed; 2, mild stenosis; 1 , severe obstruction; 0 , occluded. Glue,+++ An excess of glue was used. Inflammatory response: +++ , severe; ++ , moderate; + , mild.

*With the presence of granulocytes.

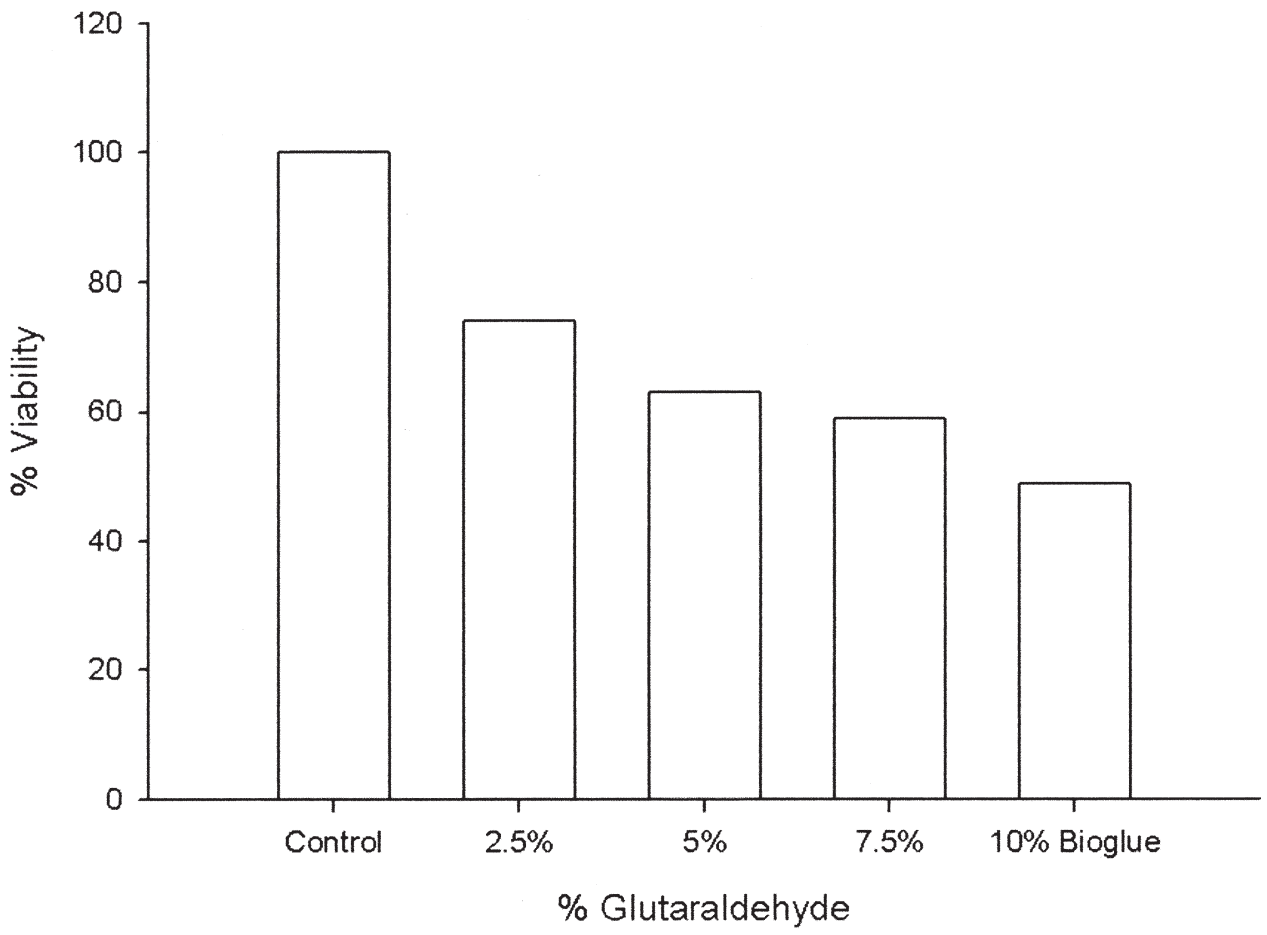

\begin{tabular}{|l|l|l|l|l|l|l|r|r|}
\hline & & & & \% viability & \% viability & \% viability & Mean & St Dev \\
\hline $24 \mathrm{~h}$ & a & b & c & a & b & c & & \\
\hline $2.5 \%$ GTA & 1.459 & 1.647 & 1.649 & 68.71 & 77.56 & 77.66 & 74.65 & 5.13 \\
\hline $5 \%$ GTA & 1.269 & 1.333 & 1.397 & 59.77 & 62.78 & 65.79 & 62.78 & 3.01 \\
\hline $7.5 \%$ GTA & 1.163 & 1.453 & 1.135 & 54.77 & 68.43 & 53.45 & 58.89 & 8.29 \\
\hline Bio Glue & 1.274 & 0.962 & 0.943 & 60 & 45.31 & 44.41 & 49.91 & 8.75 \\
\hline
\end{tabular}

Figure 7. Direct contact test. The values $a, b$, and $c$ mean that the experiments were performed in triplicate. $a, b$, and $c$, Absorbance values at $490 \mathrm{~nm}$ by means of enzyme-linked immunosorbent assay (optical density). \% Viability a = Absorbance a / Absorbance control $* 100 ; \%$ Viability b = Absorbance b / Absorbance control $* 100 ;$ and $\%$ Viability $c=$ Absorbance $c /$ Absorbance control $* 100$. Mean $=\%$ viability $a+b+c / 3$. St Dev, Standard deviation. 
tempts with nonsutured vascular anastomoses showed an excessive rate of suture-line disruption. Fibrin glue does not hold sufficient tensile strength and cannot be used as a vascular adhesive. 8 This was confirmed by means of our burst-testing results. Initially, cyanoacrylic glues held good tensile strength but caused necrosis and deterioration of the vascular wall and aneurysm formation. ${ }^{3}$ Glubran 2 (n-butyl2-cyanoacrylate), a new promising synthetic adhesive, displays better mechanical properties regarding elasticity and adherence than previously available cyanoacrylate products in the rat model. ${ }^{9}$ However, one has to bear in mind that polymerization of cyanoacrylate is an exothermic reaction. This could lead to thermal injury in vascular applications. Recently, 2-octylcyanoacrylate proved to be an effective suture-line sealant of polytetrafluoroethylene conduits with minor tissue reactivity in the sheep model. ${ }^{10}$ A preliminary clinical study of this new absorbable cyanoacrylate showed promising results in a model of arteriovenous polytetrafluoroethylene shunts for dialysis access. ${ }^{11}$ However, in both studies the adhesive is used as a sealant and not to secure the entire anastomosis. Although component protein-aldehyde adhesives definitively show sufficient tensile strength, their major disadvantages are stiffness, immunogenicity, and toxicity.

\section{Mechanical Properties}

GRF is a hard glue and can cause mechanical compression and induce irreparable damage, as reported by Martinelli and coworkers. ${ }^{12}$ Also, its mechanical properties vary a lot depending on the amount of (often unevenly dispersed) highly concentrated formaldehyde. BioGlue is also a very rigid glue. Polymerized bovine albumin forms a stiff layer and binds firmly to the adjacent tissue. This can cause substantial mechanical problems. In our clinical practice, a 57-year-old man with an ascending aortic aneurysm had a right myocardial infarction and consequent heart failure because of mechanical compression of the reimplanted right coronary artery caused by remnants of BioGlue in a Bentall procedure.

In general, 2 to $5 \mathrm{~mL}$ of autologous glue is sufficient for surgical repair in small vessels. This would equal a blood volume, before centrifugation and based on a hematocrit value of $40 \%$, of 60 to $75 \mathrm{~mL}$. The blood can be withdrawn after induction of anesthesia. Cells are then separated from the plasma by means of a quick centrifugation spin of 10 minutes. Subsequently, the plasma is transferred into the ultrafilter cartridges and centrifuged for 60 minutes. After centrifugation, cells are retransfused to the donor. An alternate approach is the use of a cell saver for obtaining the plasma. For extensive surgical intervention, blood is often withdrawn from the patient after induction and separated into plasma, red cells, and platelets. Based on the example above, one would need approximately 36 to $40 \mathrm{~mL}$ of the plasma. Although dependent on the exact protein concentrations, mixing with $7.5 \%$ of glutaraldehyde yielded the best mechanical results. The glue based on canine plasma has a slightly lower tensile strength compared with that of the commercially available BioGlue. To understand whether these lower values have a clinical relevance, the values for tensile strength at maximum load were converted into stress at maximum load because this represents force per area. The conversion gives a stress at maximum load for autologous glue made of canine proteins of $0.17 \mathrm{~N} / \mathrm{mm}^{2}$. This value is 6 times higher than the stress at maximum load $\left(0.027 \mathrm{~N} / \mathrm{mm}^{2}\right)$ obtained at a systolic blood pressure of $200 \mathrm{~mm} \mathrm{Hg}$, which makes the glue safe for surgical use. Although our autologous glue is definitively more elastic than GRF or BioGlue, it still can cause mechanical compression. At death, we found 1 occluded vessel and 3 dented anastomoses in our dog series. In all but $1 \mathrm{dog}$, an excess of glue was used. In our previous work, we were also able to validate the magnitude of the 2 different components in the final polymerization. Our experiments demonstrate that increasing glutaraldehyde concentrations mainly amplify the polymerization process. High albumin, but especially high fibrinogen, concentrations lead to extreme short polymerization times but stillelastic glue at normal glutaraldehyde concentrations (De Somer et al, 2007, unpublished data). One reason why the autologous variant is more elastic than that of commercially available glues might be the fact that apart from albumin, fibrinogen and other plasma proteins also remain present in the glue. Opposite to most proteins that have a round structure, fibrinogen has a rod-like structure. This could explain the elasticity. Nevertheless, it is clear from our experiments that the glue can cause denting of a vessel by means of external compression. Therefore the use of excessive product for whatever reason is certainly a matter of great concern in smaller-sized arteries.

\section{Immunogenicity}

The fact that some components come from another species than the acceptor might trigger immune reactions. Although its tissue toxicity is of great concern, the good thing about formaldehyde used in high concentration (37\%) is that it suppresses all immune reactions from the porcine gelatin. Therefore fully applied GRF glue is considered by the host as a foreign body with little inflammatory response. ${ }^{13}$ BioGlue is a surgical adhesive that combines $45 \%$ concentrated bovine albumin and 10\% glutaraldehyde. We already demonstrated the feasibility of coronary and vascular anastomoses by using BioGlue as the sole adhesive with an acceptable short-term patency in the dog model. ${ }^{5,14}$ However, contrary to initial work by Gundry and associates ${ }^{15}$ and 
Hewitt and colleagues ${ }^{16}$ in the herbivore model (goat and sheep), we detected a strong inflammatory response and immunogenicity to the bovine glue in the dog model. In our canine study the bovine glue was broken down by enzymes leaching out of active granulocytes. ${ }^{14}$ Likewise, LeMaire and coworkers ${ }^{17}$ found adverse reactions, such as fibrosis and strictures of vascular anastomoses, to the glue in piglets, although it is still unknown whether the same reaction might occur in children. Bovine serum albumin can act as an allergen. Fiocchi and colleagues ${ }^{18}$ reported that all children with beef allergy reacted to bovine albumin in a skin prick test. The fact that albumins from animals, which are $97 \%$ similar in structure, sequence, and function to human albumin, are recognized by the human immune system as allergens is remarkable. Glutaraldehyde 10\% (contrary to high doses of formaldehyde) does not entirely eliminate the immunogenicity. This might lead to the conclusion that immune reactions to the bovine glue could be quite different, depending on the animal model used. The reaction of herbivore animals (sheep and goat) to bovine glue is much more attenuated or even absent compared with that of omni(carni)vores that have previously been in contact with beef albumin (dog and pig). In juvenile animals and omnivores (pig and dog), the onset of the inflammatory response is early and important. The human species is predominantly omnivorous. The Mayo Clinic group found at reoperation a fierce focal acute and chronic inflammatory reaction around islets of the glue in a patient operated on 2 years previously for aortic dissection. ${ }^{19}$ BioGlue can act as an allergen in human subjects and carries the potential to sensitize patients to bovine products. Moreover, this effect could potentially manifest itself only upon subsequent antigenic contact. Because the autologous glue comprises only proteins from the acceptor, it avoids antibody formation, as shown in our immunohistologic results. Together with the sharp border between the mild inflammatory reaction and the glue deposits, the relative absence of granulocytes supports the hypothesis that this type of glue only triggers a foreign-body reaction.

\section{Toxicity}

In many centers the use of gelatin-resorcinol-formaldehyde glue as a sealant was abandoned because of a high redissection rate and false aneurysm formation in aortic dissection repair attributed to necrosis. ${ }^{20,21}$ Also, high doses of formaldehyde have a distinct toxic effect on neural tissue. Although excellent results with BioGlue in cases of acute proximal aortic dissection have been achieved, it is not without complications. Several authors have reported problems of necrosis and aneurysm formation with Bioglue similar to the GRF toxicity. ${ }^{22,23}$ Carrel and colleagues ${ }^{24}$ were the first to report that fragments of the adhesives might embolize. This has been confirmed by the interesting experimental work of LeMaire and coworkers. ${ }^{25}$ They demonstrated that the glue might gain access to the vessel lumen through suture-line needle holes (10\% of the cases in the pig model). On the other hand, Hewitt and associates ${ }^{16}$ reported, apart from encouraging experimental work, preliminary results of minimal reactions in human subjects 2 and 9 months after acute type A ascending aortic repair operations with Bioglue. Although aortic tissue could be less sensitive to the toxic effects of the glutaraldehyde, minor lesions caused by the glue might still involve a certain risk for subsequent complications in human subjects. We believe that the autologous variant offers several biologic advantages, with the absence of immune response for a start. Also, the fact that the autologous glue contains fibrinogen might be beneficial for healing. Finally, the lowered glutaraldehyde concentration will make the glue less toxic and will reduce the amount of glutaraldehyde leaching toward the surrounding tissues. Nevertheless, glutaraldehyde remains cytotoxic, even at low concentrations of $2.5 \%$. A nontoxic cross-linker would be more appropriate, provided it has a limited polymerization time for easy clinical use.

\section{Limitations of the Study}

This is a preliminary experimental study. Although autologous glue is more elastic than other commercially available protein-aldehyde adhesives, it still can cause external compression of the vessel. Another major problem is that polymerization time (dependent on the glutaraldehyde concentration) is to be kept between 1 and 2 minutes for practical use. Although we solved the immunogenicity problem by using exclusively autologous proteins, the fact that we were not able to replace toxic glutaraldehyde as a cross-linker remains in our eyes a serious drawback to free use of the adhesive in a clinical setting. Before autologous glue can be considered a true biocompatible medical device, the exact (adverse) effects of the glue on human tissue remain to be investigated.

\section{References}

1. Morikawa T. Tissue sealing. Am J Surg. 2001;182(suppl):S29-35.

2. Winterbottom N, Kuo J, Nguyen K, et al. Antigenic responses to bovine thrombin exposure during surgery: a prospective study of 309 patients. J Appl Res. 2002;2:1-12.

3. Weisberg D, Goetz RH. Necrosis of the arterial wall following application of methyl 2-cyanoacrilate. Surg Gynecol Obstet. 1964;119: 1248-52.

4. Guilmet D, Bachet J, Goudot B, et al. Use of biological glue in acute aortic dissection. J Thorac Cardiovasc Surg. 1979;77:516-21.

5. Van Nooten G, Van Belleghem Y, Foubert L, et al. An experimental model of coronary anastomoses without suturing. Cardiovasc Surg. 2003;11:80-4.

6. National Institutes of Health. Guide for the care and use of laboratory animals. Bethesda (MD): Institute of Laboratory Animal Resources, National Institutes of Health; 1985. NIH publication no. 86-23. 
7. Gibson GM, Cannon CP, Daley WL, et al. TIMI frame count: a quantitative method of assessing coronary flow. Circulation. 1996;93: 879-88.

8. Buchta C, Hedrich H, Macher M, Höcker P, Heinz R. Biochemical characterization of autologous fibrin sealants produced by CryoSeal and Vivostats in comparison to the homologous fibrin sealant product Tissucol/Tisseel. Biomaterials. 2005;26:6233-41.

9. Hall WW, Wrye SW, Banducci DR, Ehrlich P. Microvascular anastomosis using 2-octyl cyanoacrylate in the rat artery. Ann Plast Surg. 2000;44:508-11.

10. Ellman P, Reece T, Maxey T, et al. Evaluation of an absorbable cyanoacrylate adhesive as a suture line sealant. J Surg Res. 2005;125: 161-7.

11. Shenk W, Spotnitz W, Burks S, Lin P, Bush R, Lumsden A. Absorbable cyanoacrylate as a vascular hemostatic sealant: a preliminary trial. Am Surg. 2005;71:658-61.

12. Martinelli L, Graffigna A, Guarnerio M, Bonmassari R, Disertori M. Coronary artery narrowing after aortic root reconstruction with resorcin-formalin glue. Ann Thorac Surg. 2000;70:1701-2.

13. Fürst W, Banerjee A. Release of glutaraldehyde from an albuminglutaraldehyde tissue adhesive causes significant in vitro and in vivo toxicity. Ann Thorac Surg. 2005;79:1522-9.

14. Van Belleghem Y, Forsyte R, Narine K, Moerman A, Taeymans Y, Van Nooten G. Bovine glue (Bioglue $®$ ) is catabolized by enzymatic reaction in the vascular dog model. Ann Thorac Surg. 2004;77: 2177-92.

15. Gundry SR, Black K, Izutanii H. Sutureless artery bypass with Bioglue anastomoses: preliminary in vivo and in vitro results. J Thorac Cardiovasc Surg. 2000;120:473-7.
16. Hewitt CW, Marra SW, Kahn BR, et al. Bioglue surgical adhesive for thoracic aortic repair during coagulopathy: efficacy and histopathology. Ann Thorac Surg. 2001;71:1609-12.

17. LeMaire SA, Schmittling ZC, Coselli JS, et al. BioGlue surgical adhesive impairs aortic growth and causes anastomotic strictures. Ann Thorac Surg. 2002;73:1500-6.

18. Fiocchi A, Restani P, Riva E, et al. Meat allergy: I. Specific IgE to BSA and OSA in atopic beef sensitive children. J Am Coll Nutr. 1995;14:239-44.

19. Ngaage DL, Edwards WD, Bell MR, Sundt TM. A cautionary note regarding long-term sequelae of biologic glue. J Thorac Cardiovasc Surg. 2005;129:937-8.

20. Kirsch M, Ginat M, Lecerf L, Houel R, Loisance D. Aortic wall alterations after use of gelatin-resorcinol-formalin glue. Ann Thorac Surg. 2002;73:642-4.

21. Fukunaga S, Karck M, Harringer W, Cremer J, Rhein C, Haverich A. The use of gelatin-resorcin-formalin glue in acute aortic dissection type A. Eur J Cardiothorac Surg. 1999;15:564-70.

22. Kazui T, Washiyama N, Bashar AHM, et al. Role of biologic glue repair of proximal aortic dissection in the development of early and midterm redissection of the aortic root. Ann Thorac Surg. 2001;72:509-14.

23. Bingley JA, Gardner MAH, Stafford EG, et al. Late complications of tissue glues in aortic surgery. Ann Thorac Surg. 2000;69:1764-8.

24. Carrel T, Maurer M, Tkebuchava T, Niederhäuser U, Schneider J, Turina M. Embolization of biological glue during repair of aortic dissection. Ann Thorac Surg. 1995;60:1118-20.

25. LeMaire SA, Carter SA, Won T, Wang X, Conklin LD, Coselli JS. The threat of adhesive embolization: BioGlue leaks through needle holes in aortic tissue and prosthetic grafts. Ann Thorac Surg. 2005;80:106-11. 